\title{
Strengthening the Foundation for Sustainable Primary Health Care Services in Nigeria
}

\author{
Olayinka Akanke Abosede ${ }^{1^{*}}$ and Olugbenga Fola Sholeye ${ }^{2}$ \\ ${ }^{1}$ University of Lagos, Nigeria \\ ${ }^{2}$ Department of Community Medicine and Primary Care, Shagamu, Nigeria
}

"Corresponding author: Olayinka Akanke Abosede, Associate Professor, College of Medicine, University of Lagos, Lagos, Lagos State, Nigeria, Tel: 08023175899; Email: yinkabosede02@yahoo.com

Rec date: May 28, 2014, Acc date: July 21, 2014; Pub date: July 26, 2014

Copyright: (c) 2014 Olayinka AA, et al. This is an open-access article distributed under the terms of the Creative Commons Attribution License, which permits unrestricted use, distribution, and reproduction in any medium, provided the original author and source are credited.

\begin{abstract}
Since 1978's Alma-Ata Declaration on Primary Health Care (PHC) with the popular slogan "Health for All by the Year 2000" and subsequently the Millennium Development Goals (MDGs) of the Year 2000, Nigeria has made 3 major attempts to establish a sustainable PHC system and some of the reasons for failure of the first two have been identified. Even though there is some degree of general improvement, compared to other countries in the world, Nigeria's indices in spite of international aids have remained poor \{Neonatal Mortality Rate (40/000), Under-five Mortality Rate (157/000) and Maternal Mortality Ratio (545/100000).
\end{abstract}

The aim of this descriptive, interventional study is to highlight positive steps taken by governments to re-establish and revitalise PHC, especially by empowering communities, the challenges, and lessons learned as potentials for improvement of a universal, qualitative PHC system in Nigeria.

The Health Reform Laws and Strategic Development Plans emphasize commitment to the promotion and protection of the health of the people as an essential service for sustained socio-economic development and better quality of life. Community structures (Local Government Health Authorities-LGHAs, Ward Health CommitteesWHCs and Health Facility Management Teams) backed by the law were either newly established or reconstituted and empowered.

The study describes measures taken to strengthen the weak foundation of the PHC system in Lagos State (the study's index state), the outputs, outcomes and potential impacts. The challenges and lessons learned from dealing with them can be projected for improved national coverage.

Keywords: Primary health care; Ward health system; Enabling law; Community participation; Human resource for health; Capacity building

\section{Introduction}

The Alma Ata Declaration of 1978 [1] expressed the need for urgent action by all governments, all health and development workers, and the world community to protect and promote the health of all the people of the world. It strongly reaffirmed that health, a state of complete physical, mental and social wellbeing, and not merely the absence of disease or infirmity, is a fundamental human right and that the attainment of the highest possible level of health is a most important world-wide social goal whose realization requires the action of many other social and economic sectors in addition to the health sector.

PHC has been identified as the key to attaining this as part of development in the spirit of social justice. It relies, at local and referral levels, on health workers, including physicians, nurses, midwives and community workers as applicable, as well as traditional practitioners as needed. All must be suitably trained socially and technically to work as a health team so as to respond to the expressed health needs of the community.
There have been 3 major attempts at PHC implementation in Nigeria. The first attempt (1975-1983) was by the Federal Ministry of Health through the Basic Health Services Implementation Agency.

Schools of Health Technology were built for the training of middle level health manpower to form the PHC Team with doctors. In the absence of doctors (who were inequitably distributed) Community Health Officers (CHOs) or Community Health Extension Workers (CHEWs) were to head the Team. A committee of the FMOH developed a National Health Policy that identified PHC as the cornerstone to the National Health System. Even though the strategies were promotion of community mobilisation, involvement of other sectors, functional integration and strengthening of managerial processes, there were problems with implementation.

The main problems of this attempt were identified as poor community participation $(100 \%$ of resources provided by government), faulty citing of health facilities, stolen equipment, lack of political commitment as well as inadequate orientation and distribution of the health workforce. Consequently health indices and primary health care coverage and quality remained poor.

The second attempt, the District Health System (1986-1992) started with the development of "Project Formulation Documents" or Action Plans that were funded by the Federal government in 52 selected pilot 
Page 2 of 9

LGs. Village and District Health Committees were formed but the problems identified for this attempt were similar to the first. Communities did not have ownership of their PHC facilities and did not participate actively in the development of the Action Plans for their communities. Poor funding, lack of appropriate infrastructure, equipment, drugs and materials persisted. This system was strengthened by the Bamako Initiative activities in 1988 when PHC facilities had seed drugs to operate Drug Revolving Funds jointly administered with their Community Development Committees. However, guidelines for the formation of Community/Village Development Committees were not followed, there was paucity of basic health statistics and inequitable distribution of manpower and poor logistics persisted. Even though the Law establishing the National Primary Health Care Development Agency (NPHCDA) was enacted and the agency with 6 zonal and 36 state+the FCT offices were set up in 1992, there was no similar law backing community structures for health. Consequently, Community Committees became dysfunctional, PHC facilities were bypassed and health indices, primary health care coverage and quality remained poor [2].

In response to recommendations of international partners (3rd attempt) the District Health System was replaced by the Ward Health System (WHS) in the Year 2000. The objectives of this attempt were to improve knowledge, attitude and practice on health issues, encourage self-reliance, reduce maternal and infant mortality by $25 \%$ in target wards within 2 years, improve immunisation coverage by $20 \%$ in 2 years, improve nutritional status by $20 \%$ especially among under-fives, make essential drugs available, affordable and accessible, encourage collaboration between stakeholders as well as promote poverty alleviation activities.

Two hundred PHC facilities were built in 200 model wards, a ward being the smallest geopolitical unit from which a councillor is elected. In the spirit of community ownership, the facilities were handed over to the Community Development Committees (CDCs) whose capacities were enhanced for effective management of the facilities and community-based intervention programmes.

Over a period of 12 years (2000 to 2012), several programmes including the Minimum Health Care Package, Integrated Management of Childhood Illnesses (IMCI), Expanded Programme of Immunisation (EPI), National Immunisation Days (NIPDs), Integrated Maternal, New-born and Child Health (IMNCH) Services etc have been introduced to strengthen the WHS which is still not fully operational in any part of the country. Attempts have also been made at Community based financing, National Health Management Information System based on measurable indicators, equitable use of resources, and the development and use of relevant manpower has continued. However,

"Lack of effective stewardship role of government, fragmented health service delivery, inadequate and inefficient financing, weak health infrastructure, mal-distribution of health workforce and poor coordination" $[3,4]$ amongst key players continue to be identified as the major impediments to the establishment of an efficient, effective health (PHC) system in the country. Up to date, health is on the Concurrent List and there is no specific fund for PHC. The proposed National Health Bill (2008) that is yet to be signed is expected to correct inadequate/inefficient management of available resources, a major factor responsible for the slow pace at which the country is moving towards the achievement of the MDGs $[5,6]$.

\section{Description of Study Area}

Nigeria the most populous African country in sub-Saharan West Africa has a population of about 167 million. It has 36 states and a Federal Capital Territory. There are officially 8,812 wards each with a population of 30000 to 50000 . Nigeria's overall performance in health was ranked $187^{\text {th }}$ position among 191 member states by the WHO in the Year 2000 [6]. According to the National Demographic Health Survey (NDHS), immunisation coverage was $23 \%$, only $6 \%$ of underfives slept under Insecticide Treated Nets (ITNs) and less than half of pregnant women were delivered by skilled birth attendants. Maternal Mortality, Neonatal, Infant and Under-five Mortality remain unacceptably high [7]. There is gross inequity in access to health care and varying community response to health interventions such that indices for health vary across the country. For example, maternal mortality in the south-west is about 500 compared to up to 2000 in some parts of the north. In order to address these challenges, the costed National Strategic Health Development Plan of 2009 to 2015 with evidence-based priority interventions was developed as a guide for states and LGs.

Lagos State, the study index, often referred to as mini Nigeria because of its cosmopolitan nature is fast becoming a mega city. Lagos State has a Land Mass Area of 358, 861 hectares (3,577 square km). The population is by projection now about 20 million with a Population Density of 4193 persons per sq.km. In the (Built-Up- Area it is more than 20000 persons per square $\mathrm{km}$ ). The Annual Population Growth Rate is $8 \%$ meaning that Lagos will be the third largest city in the world by 2015 after Tokyo in Japan and Mumbai in India (UN). Comparatively, the rate for Nigeria is $4-5 \%$ and the Global rate is $2 \%$.

As the cost of living in urban areas is increasing, large numbers of residents are moving to the rural communities, where access to quality health services may be lacking. The Lagos State Health Reform Law of Year 2006 describes the existing gross inequality in the health status of the people particularly between difficult to reach areas and urban ones as "politically, socially and economically unacceptable" [7].

The state has 20 Local Governments Authorities but administratively, it has in addition, 37 Local Council Development Areas and 376 wards. Not all the wards have PHC facilities even though over the study period there was a total of 277 of them with 234 functional. In addition, there are 24 secondary health facilities and 6 tertiary ones. The implementation of PHC in the State some years before the Health Sector Reform Law had been generally ineffective.

The major reasons identified for the poor state of implementation, similar to the national ones were poor coordination, lack of commitment and poor funding by Government, low PHC budget performance, non-establishment of PHC structures, low level of community involvement, ownership and participation, dilapidated infrastructure, inadequate $\mathrm{PHC}$ manpower and lack of basic drugs, materials and equipment $[5,7]$.

The aim of this study is to highlight the challenges and lessons learned from the implementation of the National/State Health Reform Laws as potential for improved qualitative and universal PHC coverage in Nigeria. 


\section{Interventions}

\section{Enactment and implementation of the Health Reform Law}

The strategies of Lagos State for PHC revitalisation were (1) Enactment of the Health Sector Reform Law (2) Establishment of PHC Management Structures and (3) Implementation of the new policy on PHC revitalization including:

- PHC Personnel Development and Management.

- Massive Development of PHC Infrastructure through Upgrading of Existing Health Facilities into model (Flagship) PHCs.

- $\quad$ Providing the Scope of Services under Ward Minimum Health Care Package (WMHCP) and Integrated Management of Maternal, New-born and Child Health (IMNCH) in the Flagship PHCs.

- Supply of Essential Drugs through Drug Revolving Fund (DRF).

- Quality Control and Effective Monitoring and Evaluation.

It was with a view to addressing the above that the State Government incorporated PHC Reform into the Lagos State Health Sector Reform Law of 2006 and established the Lagos State Primary Health Care Board. The objective of the Law is to regulate and provide uniformity for health services across the State through:

- Establishment of a Heath System which encompasses public and private providers of health services and provide the population of the state the best possible health services that are affordable with available resources.

- $\quad$ Setting out rights and duties of health care providers, health Workers, health establishments and users.

In accordance with the prescriptions of the HSRL, government proceeded with:

\section{Selection and inauguration of the State Primary Health Care Board}

Members of the Board were selected by the State Governor with the assistance of the Commissioner for Health. It was inaugurated according to section 85 of the Lagos State Health Sector Reform Law of 2006, in February 2009 with the aim of collaborating with the Local Governments and Local Council Development Areas in the state to achieve effective and efficient implementation of Primary Health Care in the State. The Board comprised 6 relevant community members, the Chairman (a community physician), 4 health care professionals (public and private) and 6 representatives of relevant ministries (Information, Finance, Local Government and Chieftaincy Affairs, Health and Economic Planning and Budget). It started coordinating PHC programmes in the state with a vision to develop Primary Health Care to a level where services will be accessible, acceptable and affordable to the people of the State. Also to ensure increased utilization of Primary Health Care facilities with a view to reducing disease burden in the state and achieving improvement in health status indicators (Infant Mortality Rate, Maternal Mortality Ratio, Life Expectance at Birth, etc.)

Based on the PHC reform, focus on universal access and social health protection the Board at inauguration highlighted its initial priorities and immediately commenced the following:

- Advocacy to Local Government policy makers and community opinion leaders
- Sensitisation of the general public to create awareness and arouse behaviour change for healthier lifestyles and environmental protection.

- Community diagnosis and generation of baseline data with full community participation

- Institution of planning and evidence-based PHC implementation through Action Plans generated by communities

- Personnel auditing to ensure adequacy of human resources for $\mathrm{PHC}$

- Completion of the inventory of PHC infrastructure and equipment to facilitate the implementation of the policy of one PHC facility per ward.

- Determination of capacity development needs of PHC providers and establishment of teams who will facilitate access to appropriate use of technology and medicines.

- $\quad$ Establishment and/or empowerment of Ward Development Committees and institutionalisation of participation of civil society in policy dialogue and accountability mechanisms.

- $\quad$ Promotion of effective disease surveillance/ response and implementation of an efficient two-way referral system

Towards achieving effective collaboration, advocacy visits were paid to and/or meetings held with various stakeholders including the:

- Lagos State Government executives (Deputy Governor and former Commissioner for Women affairs and Poverty Alleviation, Secretary to Government, Head of Service, Commissioners of relevant ministries e.g. Health, the supervising ministry, Finance, Budget and Planning, Information, Local Government and Chieftaincy Affairs), Lagos State House Committee on Health, Local Government Service Commission, Hospital Services Commission, and AIDS Control Agency).

- LGs/LCDAs, LGHAs, WHCs

- National Primary Health Care Development Agency

- $\quad$ Provosts and Departments of Community Health of the Lagos State College of Medicine and the College of Medicine of the University of Lagos.

- Lagos State Schools of Health Technology, Public Health Nursing and Midwifery.

- Development Partners and Projects (WHO, UNICEF, USAID, UNFPA, DFID- PATHS 2, JICA, EU PRIME, SuNMaP and others).

- All cadres of Primary Health Care Personnel.

\section{Constitution and swearing in of the Local Government Health Authorities (LGHAs)}

LGHAs were constituted by the LG/LCDA Chairmen and Supervisory Councillors for Health, with the Assistance of the Medical Officers of Health. All except 3 (Lagos Island LG, Agboyi-Ketu LCDA and Odi Olowo LCDA) were sworn in by August 2009. Members include a chairman (experienced health practitioner with minimum of 10 year's experience), 2 community members of proven integrity (one female), representative of Traditional Medicine Board and the Medical Officer of Health of the LG/LCDA (Board Secretary). Their functions include: 
- Setting out targets in line with all overall objectives of setting up the Primary Health Care (PHC) Facilities and taking due cognizance of government policy directives as, directed by the Executive Chairman of the Local Government Area, in respect of economic, financial, operational and administrative programmes:

\section{- $\quad$ Administration of PHC staff on GL 01-06.}

\section{The Ward Health Committees (WHCs)}

WHCs were constituted and sworn in by the LG/LCDA according to the Law with 5 members; a part-time chairman (knowledgeable in health), 3 other persons representing the Community (a representative of youths, preferably female, a Traditional Birth Attendant, a community leader e.g. from one of the professional groups in the community) and the Officer-in-Charge of the Health Facility Management Team (The Officer in Charge being the most Senior Health Worker posted to the Facility). There functions are to:

- Assist the Medical Officer of Health in the day to day management of the health facility and to ensure proper medical care of patients

Make proposals with regard to the Overall planning, expansion, development and maintenance of the health institutions within the jurisdiction. Assess available manpower and client load in their health facilities

\section{Implementing Staff Training programmes} wards

Participate actively in every stage of PHC revitalisation in their

Determine the health and health related challenges of communities

Identify determinants of their health challenges

\section{The Health Facility Management Team (HFMT)}

For each PHC facility was constituted according to the Health Reform Law Guidelines to complement the WHC activities. The most senior person who is in charge of the facility is the secretary to the Management Team comprising the heads of the units in the facility.

\section{Baseline situation analysis}

As part of the preliminary activities for revitalisation of Primary Health Care (PHC) in the State, a situation analysis of one static facility per Local Government Authority (LGA) was conducted in the 20 original LGAs. The objectives of the study were to:

- Assess the suitability of selected static facilities for providing PHC services (physical structures, equipment, environment, accessibility)

\section{- Assess available manpower and client load}

- Determine requirements for upgrading selected facilities as models for PHC

Each PHC facility was assessed for infrastructure, equipment, manpower needs and scope of service provision. The facilities were selected by Primary Health Care providers who were participants at a fact-finding workshop. Selection was based on criteria including accessibility, client load and manpower. Investigators were provided a checklist used to assess the buildings, equipment, health manpower, services available and the client load. Based on the results of the survey, fifty-seven (57) of the existing Primary Health Centres in the State were renovated and provided with basic PHC equipment, drugs and materials. Thirty (30) additional PHCs were renovated, seventy (70) new PHCs were constructed with funding from Conditional Grants/State government/HSDP/LGs and LCDAs. By the Year 2012, the State had 277 PHCs, with only 243 functional and 34 nonfunctional because of gross manpower shortage.

\section{PHC staff development and management}

Two 3 days training workshops on the Ward Health System were organised for all cadres of PHC staff selected from all PHCs in the state totalling 300 in 2 batches. Several continuous training workshops to improve the quality of care were organised as on-the-job training with assistance from partners (Japan International Cooperation Agency (JICA), Partnership for Transforming Health Systems (PATHS 2), SunMap, WHO, UNICEF) in assisted LGs to be scaled up to others by the Board. The state commenced Continuing Medical Education programmes made compulsory for all doctors by the National Medical and Dental Council. Practicing licences are not renewed unless there is evidence of attendance with a minimum score of 20 units per annum.

The challenge of conflict in responsibilities of the PHC Board and Local government service commission was resolved in accordance with the concept of "PHC under One Roof". The SMOH requested for formal handing over of the management of PHC staff from the Local Government Service Commission to the PHC Board.

The recommended composition of Senior Health Workers in a PHC providing 24 hours services presented to the House of Representatives included one (1) Medical Officer of Health, 3 Medical Officers, 10 Staff Nurse/Midwives, 1 Pharmacist, 3 Pharmacy Technicians, 2 Community Health Officers, 6 Community Health Extension Workers, 1 Laboratory Scientist, 3 Laboratory Technicians, 1 Medical Records Officer, 3 Medical Records Technician and at least 1 Environmental Health Officer. Additional staffing for the existing 277 PHCs and the budget requirements were presented.

The recruitment of additional staff to fill gaps identified in the baseline survey only got to the stage of interviews of the various cadres because of financial constraints. As an alternative, unemployed graduates were recruited to assist PHC staff.

\section{Capacity building for community governing bodies}

In order to develop the capacity of LGHAs, a 2 day capacity building workshop on Management of Primary Health Care was organized for the LGHA members in 8 batches of 42 participants each by the PHC Board in collaboration with PATHS 2. Fifty-four out of the 57 LGHAs inaugurated attended the workshops that lasted 5 days each.

As a follow up to the training, the LGHAs as instructed commenced some of the following functions to varying degrees (not yet assessed) in their respective LGs/LCDAs:

- $\quad$ Liaising with the LGs/LCDAs to constitute Ward Health Committees according to the SHRL Guidelines and training of members in the next one month.

- Setting out targets in line with the overall objectives of PHC.

- Implementation of broad policy measures on Primary Health Care Development Plans. 
Page 5 of 9

- Consideration of plans and budgetary proposals of the Ward Health Committees.

- Coordination and integration of various health services within their jurisdiction.

- Conduct of Community Diagnosis towards development of Ward Health Plans and LG/LCDA Health Plans

- Coordination of roll-out of Integrated Maternal, Newborn and Child Health (IMNCH) strategy and implementation of the other components of the Ward Minimum Health Care Package (Health Education and Promotion, Nutrition and Screening for Communicable and Non-communicable Diseases) at the Primary Health Centre.

- Supervision of the implementation of Ward Action Plans developed by the WHCs.

Presentations by PHC Board members and a Training Manual developed with PATHS2 were used for training of WHCs. They were empowered to conduct community diagnosis and situation analysis in their wards. Five trainers from the Board and 2 representatives of partners commenced the training with 75 of the 1,880 members of WHCs. In addition to implementation of the Minimum Primary Health Care Package, the Board promoted a comprehensive response to people's expectations and needs, spanning the range of risks and illnesses in the communities.

Classroom Exercises included (a) In-Depth Interview of Key Informants. Three (3) participants played the roles interviewing key informants on specific topics earlier identified as challenges or determinants of poor health status in the community e.g. attitudinal, socio-cultural, environmental or behavioural factors contributing to low PHC service utilisation, lifestyle contributory to health problems e.g. smoking, diet and knowledge of health promotive practices e.g. breast self-examination, prevention of diarrhoeas/Cholera etc. (b) Focus Group Discussion was coordinated by a trainer while participants acted other roles.

The methodology for the design of Household Survey Instruments was explained and participants learned how to obtain information at the household level. Emphasis was laid on attitude and the style of probing for answers that encourage correct responses. The instruments were translated into local language and participants suggested improvements.

Field Exercise was conducted by participants using the 3 data collection methods (Key informant Interviews, FGD, household survey with questionnaires). Participants were accompanied by facilitators to assigned communities. Participants shared experiences and scoring was on: (a) attitude and confidence (b) interviewing skill (introduction, maintenance of rapport, clarity and orderliness) and (c) accuracy in filling the form.

\section{Funding and cost of interventions}

Funding was from the state government pending the operationalization of the National Health Bill. This was augmented by contributions from partners for training workshops.

The overall cost of the interventions is not known because the expenditures on most of it are not disclosed.

\section{Outcomes of Interventions}

\section{Political commitment}

There is apparent commitment of federal, state and Local Governments to PHC but a higher level of commitment in terms of funding and employment of adequate human resource at this level is crucial to a stable foundation. There has been a high response from state governments to implement Health Reforms. This was highest in Lagos, the FCT and Sokoto States. Twenty-seven (27) out of 36 states +FCT (70.27\%) including Lagos, Ondo, Ekiti, Ogun, Bauchi, Adamawa, Yobe, Gombe, FCT, Nassarawa, Niger, Kwara, Benue, Kogi, Edo, Delta, Rivers, Cross River, Katsina, Jigawa, Sokoto, Kano, Kebbi, Kaduna, Zamfara, and Abia inaugurated their PHC Boards/Agencies and enacted laws to support them. Only 10 (27.03\%) including Ebonyi, Imo, Edo, Oyo, Plateau, Taraba, Bornu, Kaduna, Anambra and Enugu were yet to do so at the conclusion of this study.

\section{Personnel development and management}

Having taken over the responsibility for senior PHC staff, the PHC Board has been able to train a critical mass of trainers of LGHAs and WHCs that will continue to train both groups. In spite of approval of the proposal for additional PHC staff by the House of Assembly, financial challenges stalled the recruitment of all cadres. Only 5 (8.77\%) of the 57 model/flagship ( 24 hours) facilities or $1.81 \%$ of 277 existing PHC facilities were fully staffed at the conclusion of the study. The impact and cost-effectiveness of the alternative intervention, the recruitment of unemployed graduate volunteers instead of trained PHC personnel to assist in clinics is yet to be assessed.

\section{Development of PHC infrastructure in the state}

Following renovation and equipment of facilities, it became more possible and reasonable to re-deploy staff to communities where they are resident. This reduced travel time drastically making staff more available to clients.

Funding of PHC remains a challenge because it is still through the state government to LGs/LCDAs in spite of inauguration of the PHC Board. When the National Health Bill is operational it will be from Federal government through the PHC Board to LGHAs and then to WHCs.

Payments for services remain through Fee for Services and Drug Revolving Fund even though states have started experimenting with Community Based Health Insurance Scheme. The National Health Insurance Scheme is still at a rudimentary stage.

\section{Challenges of community governing bodies for health}

Initial challenges faced by the PHC Board included lack of a take-off grant, adequate office accommodation for the Board and 10 Directorates and conflicting roles with the Local Government Service Commission. These were addressed by the State Ministry of Health but others include resistance from LG/LCDAs for sustenance of the community governing bodies pending the signing of the National Health Bill into law and subsequent disbursement of funds to operate Ward Operational Plans.

\section{Results of Training Workshops}




\begin{tabular}{|c|c|c|c|c|c|c|c|c|c|c|}
\hline Grp & Zone & \multicolumn{3}{|c|}{$\begin{array}{l}\text { Participant s } \\
\text { T M F }\end{array}$} & $\begin{array}{l}\text { Pre } \\
\text { test }\end{array}$ & $\begin{array}{l}\text { Post } \\
\text { test }\end{array}$ & $\begin{array}{l}T \text { test } \\
(P=)\end{array}$ & Mode & Mean & Median \\
\hline 1 & Lagos West1 & \multirow[t]{2}{*}{61} & 24 & 7 & $\begin{array}{l}\text { Highest } 40 \\
\text { Lowest } 10\end{array}$ & $\begin{array}{l}45 \\
20\end{array}$ & \multirow{2}{*}{$\begin{array}{l}16.50 \\
(0.039) \\
17.50 \\
(0.036)\end{array}$} & $\begin{array}{l}\text { Pre } 36 \\
\text { Post } 36\end{array}$ & $\begin{array}{l}32 \\
36\end{array}$ & $\begin{array}{l}32 \\
37\end{array}$ \\
\hline 2 & (15LGs/LCDAs) & & 22 & 8 & $\begin{array}{l}\text { Highest } 39 \\
\text { Lowest } 30\end{array}$ & $\begin{array}{l}44 \\
15\end{array}$ & & $\begin{array}{l}\text { Pre } 39 \\
\text { Post } 40\end{array}$ & $\begin{array}{l}34 \\
38\end{array}$ & $\begin{array}{l}34.8 \\
36\end{array}$ \\
\hline 3 & Lagos West2 & \multirow[t]{2}{*}{80} & 36 & 8 & $\begin{array}{l}\text { Highest } 45 \\
\text { Lowest } 2\end{array}$ & $\begin{array}{l}47 \\
13\end{array}$ & $\begin{array}{l}3.25 \\
(0.190)\end{array}$ & $\begin{array}{l}\text { Pre } 38 \\
\text { Pre } 35\end{array}$ & $\begin{array}{l}35 \\
19\end{array}$ & $\begin{array}{l}30.2 \\
29.9\end{array}$ \\
\hline 4 & (13LGs/LCDAs) & & 27 & 9 & $\begin{array}{l}\text { Highest } 41 \\
\text { Lowest } 7\end{array}$ & $\begin{array}{l}46 \\
27\end{array}$ & $\begin{array}{l}6.80 \\
(0.093)\end{array}$ & $\begin{array}{l}\text { Pre } 45 \\
\text { Post } 39\end{array}$ & $\begin{array}{l}30 \\
40\end{array}$ & $\begin{array}{l}28 \\
38\end{array}$ \\
\hline 5 & Lagos Central & \multirow[t]{2}{*}{60} & 14 & 7 & $\begin{array}{l}\text { Highest } 41 \\
\text { Lowest } 6\end{array}$ & $\begin{array}{l}45 \\
23\end{array}$ & $\begin{array}{l}29.40 \\
(0.022)\end{array}$ & $\begin{array}{l}\text { Pre } 34 \\
\text { Post } 37\end{array}$ & $\begin{array}{l}36.5 \\
39\end{array}$ & $\begin{array}{l}30.9 \\
38.2\end{array}$ \\
\hline 6 & (15LGs/LCDAs) & & 25 & 14 & $\begin{array}{l}\text { Highest } 41 \\
\text { Lowest } 7\end{array}$ & $\begin{array}{l}43 \\
15\end{array}$ & $\begin{array}{l}17.50 \\
(0.036)\end{array}$ & $\begin{array}{l}\text { Pre } 38 \\
\text { Post } 39\end{array}$ & $\begin{array}{l}34 \\
38\end{array}$ & $\begin{array}{l}34.2 \\
35.8\end{array}$ \\
\hline 7 & Lagos East & \multirow[t]{2}{*}{72} & 24 & 18 & $\begin{array}{l}\text { Highest } 44 \\
\text { Lowest } 13\end{array}$ & $\begin{array}{l}43 \\
25\end{array}$ & $\begin{array}{l}17.00 \\
(0.037)\end{array}$ & $\begin{array}{l}\text { Pre } 34 \\
\text { Post } 38\end{array}$ & $\begin{array}{l}33 \\
37\end{array}$ & $\begin{array}{l}29 \\
35.7\end{array}$ \\
\hline 8 & (15LGs/LCDAs) & & 19 & 11 & $\begin{array}{l}\text { Highest } 46 \\
\text { Lowest } 31\end{array}$ & $\begin{array}{l}45 \\
31\end{array}$ & $\begin{array}{l}23.00 \\
(0.028)\end{array}$ & $\begin{array}{l}\text { Pre } 34 \\
\text { Post } 42\end{array}$ & $\begin{array}{l}34 \\
37\end{array}$ & $\begin{array}{l}32.5 \\
35\end{array}$ \\
\hline & Total & 273 & 191 & 82 & & & & & & \\
\hline
\end{tabular}

Table 1: Results of tests capacity building workshop for LGHA members

Grp=Group, T=Total, M=Male, Female=Female

\begin{tabular}{|c|c|c|c|c|c|c|c|c|}
\hline No & WARDS & WHC & Batch & $\begin{array}{l}\text { Highe } \\
\text { st } \\
\text { Mark } \\
(50)\end{array}$ & $\begin{array}{l}\text { Lowe } \\
\text { st } \\
\text { Mark } \\
(0)\end{array}$ & Mode & $\begin{array}{l}\text { Mea } \\
\mathrm{n}\end{array}$ & $\begin{array}{l}\text { Media } \\
\mathrm{n}\end{array}$ \\
\hline & & & 1st & & & & & \\
\hline 1. & Ikate-Lekki & 5 & \multirow{5}{*}{$\begin{array}{l}\text { PRE- } \\
\text { TEST } \\
\text { POST- } \\
\text { TEST }\end{array}$} & \multirow[t]{3}{*}{34} & \multirow[t]{3}{*}{12} & \multirow[t]{3}{*}{34} & \multirow[t]{3}{*}{33} & \multirow[t]{3}{*}{31} \\
\hline 2. & Badore & 5 & & & & & & \\
\hline 3. & Akere & 5 & & & & & & \\
\hline 4. & $\begin{array}{l}\text { BabatundeAy } \\
\text { ilara }\end{array}$ & 5 & & \multirow[t]{2}{*}{42} & \multirow[t]{2}{*}{21} & \multirow[t]{2}{*}{35} & \multirow[t]{2}{*}{34} & \multirow[t]{2}{*}{34} \\
\hline 5. & Baale & 4 & & & & & & \\
\hline 6. & ljora & 5 & \multirow{3}{*}{$\begin{array}{l}\text { 2nd } \\
\text { PRE- } \\
\text { TEST } \\
\text { POST- } \\
\text { TEST }\end{array}$} & \multirow[t]{2}{*}{41} & \multirow[t]{2}{*}{5} & \multirow[t]{2}{*}{35} & \multirow[t]{2}{*}{33} & \multirow[t]{2}{*}{35} \\
\hline 7. & Gaskiya & 5 & & & & & & \\
\hline 8. & Ikoyi & 5 & & 43 & 29 & 39 & 38 & 37 \\
\hline
\end{tabular}

Table 2: Capacity building workshop for members of the Ward Health Committee (WHC) on PHC management

$$
{ }^{\star}=\text { missing information }
$$

\section{Consequences of the intervention}

There was an initial negative reaction of the LG/LCDA Chairmen to the PHC Board that was seen as an unnecessary parastatal. LGs/ LCDAs did not release or contribute from PHC allocation to the Board. The State Ministry of Health resisted the transfer of some departments (e.g. Health Education) and staff to the Board. It was however the same ministry through which the Board was able to obtain funds from government, assistance from other ministries and take over responsibility for senior PHC staff.

The intervention has led to the building, renovation, additional staffing and equipment of more facilities. It has however resulted in more demands and petitions from underserved communities. Inequality in health care resource distribution and provision has also become more visible. Even though some senior PHC staff had complained when seconded to secondary facilities, they preferred to continue working where they were being close to retirement. The redeployment of PHC staff to LGs/LCDAs where they are resident was however well received.

Upgrading of facilities to provide 24 hour services has led to more clients and more deliveries at the PHC level. This however does not seem to have reduced the crowd at secondary and tertiary facilities. Even though 57 LGs/LCDAs were provided ambulances, the two-way referral system between the 3 tiers of health care is yet to be well established.

Data collection especially from private facilities in wards is still facing challenges in spite of the state's efforts to enforce prompt submission of filled national health management information Forms. 
Enforcement of the standards for quality health care in private facilities by the State's Health Facility Accreditation and Management Agency is still in a rudimentary stage. The building of government facilities where only private facilities existed before may lead to positive completion and better client care.

Judged by the enthusiasm of community committees that have responded promptly for meetings and trainings, it will be correct to say that if the committees remain functional, the challenges of nonparticipation of communities will be overcome.

\begin{tabular}{|l|l|l|l|l|l|}
\hline WHC Trainers (N=44) \\
\hline & $\begin{array}{l}\text { Highest } \\
\text { Score (50) }\end{array}$ & $\begin{array}{l}\text { Lowest } \\
\text { Score(0) }\end{array}$ & Mode & Mean & Median \\
\hline PRE-TEST & 45 & 21 & 45 & 38.1 & 33 \\
\hline POST TEST & 47 & 27 & 37 & 40 & 37 \\
\hline
\end{tabular}

Table 3: Results of capacity building workshop for a critical mass of trainers on PHC management

\section{Discussion}

The implementation of the Health Reform Laws has started a revitalisation of $\mathrm{PHC}$ with more appropriate involvement of the people, improved resource management (human, financial, data/ logistics, drugs/supplies) as well as an apparent higher level of service utilisation. The expected impact of these is general improvement of health status and better health indices for Lagos State and the country.

\section{Political commitment}

The apparent commitment of federal, some states and some Local Governments to PHC must be sustained. Also, their commitment in terms of funding, community involvement in policy decisions and employment of adequate human resource is crucial to the sustenance of a stable PHC system foundation. Most PHC facilities in the country as in Lagos State do not have adequate staff to provide 24 hour services or take deliveries because required staff have not been employed or the conditions of service are poor and not acceptable. Consequently, access to services is limited and communities patronise available alternatives; secondary and tertiary hospitals or expensive private clinics, patent medicine sellers and traditional practitioners or resort to unsafe self-medication. This is also one major reason for overcrowding, long waiting times and reduced quality of care at the higher tiers of health care.

\section{Infrastructure}

There is hardly any ward in the country without infrastructure that can be utilized for PHC services. Multipurpose community halls can be used as long as relevant staff, equipment, materials and drugs are available. Also private facilities are available even where there are no government ones, so, logistics could be worked out for private-public partnerships especially for the National Health Insurance Scheme. Renovation of existing infrastructures is cost-effective and promotes better coverage.

\section{Community participation, health and development}

There is no doubt that the promotion and protection of the health of people in all parts of the country is essential to sustained economic and social development. Besides, people have a right to their health care. The health system must be such that will permit them to lead a socially and economically productive life. Recognising that people have the right and duty to participate individually and collectively in the planning and implementation of their health care, the country and state Health Sector Reform Laws lay emphasis on the responsibilities of the people. Managerial capacity building for community governing bodies has reawakened involvement in interventions, a necessity for sustainability. Fortunately, there are resources in every ward waiting to be optimally utilized for PHC.

The Federal and state governments in Nigeria have taken steps jointly and unilaterally to various degrees to ensure the institution of viable and sustainable community structures to implement PHC interventions. Globally, the most positive and effective health reforms are those that have implemented interventions by optimally applying the principles of PHC [8-22]. PHC is defined as "essential health care based on practical, scientifically sound and socially acceptable methods and technology made universally accessible to individuals and families in the community through their full participation and at a cost that the community can afford to maintain at every stage of their development in the spirit of self-reliance and self-determination. It forms an integral part of both the country's health system, of which it is the central function and main focus, and of the overall social and economic development of the community" [1].

Assessments of the application of PHC principles and attainment of "Health For All By The Year 2000" have shown that while countries mostly in the developed world made acceptable adjustments, African countries lagged behind for the following reasons among others: (1) efforts to restructure health systems were handicapped by lack of drugs (2) expensive drugs (3) poor quality of health care services (4) poor quality of life

The same trend can be said of the attainment of the MDGs by 2015 [6] One major attempt to improve performance was The Bamako Initiative (BI) that targeted all mothers and children especially in remote, rural communities of countries identified by WHO (Africa Region) and UNICEF, south of the Sahara. The BI objectives which are still relevant today were to (i) promote self-reliance (ii) use funds from DRF to support other PHC programmes and (iii) promote health management at LG and community levels [7].

Africa Ministers of Health Agreements for BI that have only been partly fulfilled were: (i) encouragement of social mobilisation to promote community participation (ii) ensurance of regular supply of essential drugs (iii) Implementation of self-funding for drugs at PHC Level (DRF) and (iv) PHC services to be available and affordable. Most of the targeted countries did not achieve the objectives by the Year 2000 [8] and various efforts are still being made to ensure proper development of PHC systems ( review of National Health Policies, plans and programmes aimed at nurturing and sustaining PHC, mobilization of national and international resources for support and investment in PHC) [8].

The Ward Health System in Nigeria as designed now will help communities to develop capacity to own the health system that will be used to deliver services identified in the "Minimum Health Care Package" with effective community-based systems of financing as much as possible. It will develop and use relevant manpower, institute 
Page 8 of 9

a system for collecting health information based on measurable indicators and use them for managing the health system. In addition, it is designed to ensure equitable distribution of facilities and resources as well as to correct misconceptions e.g. PHC is for the poor, concerns only children and women, is only for immunization, family planning / antenatal, lack; qualified people etc.

A study done three years after the commencement of the WHS in Nigeria found that, high percentages of the stakeholders, especially WHC/WDC were not well informed [9]. In countries like Ghana where community structures are well established, intervention programmes e.g. Malaria project are being sustained and have wide coverage [10].

The Composition of Governing Bodies may vary with countries. One major health reform in Nigeria is the creation of State Agencies/ Boards. The Law for Lagos State made provisions for the establishment of community structures that are fully backed by the law (first in the country) while executing programmes with drastic measures for resuscitating PHC in the state. The strategy was Integration of all PHC services delivered under one authority.

\section{Human resource and capacity building}

There are human resources with health knowledge and potentials for effective leadership in the Ward Health System. Their performances in the pre-tests on management of the WHS showed some degree of baseline knowledge especially among the health professionals (some retired) and the PHC staff who had been recently trained by the Board. They scored high in the pre-test and there was no significant difference between their pre and post test scores (Tables 1-3). However overall, there was significant improvement in knowledge after the training workshops. The increasing trend of movement of educated retirees and younger ones to suburbs and rural areas in search of cheaper accommodation is a welcome development. Emphasis should now be on effective, appropriate knowledge transfer.

A major challenge to health manpower is brain drain to other countries. Nigeria has adequate training facilities for high, middle and low health manpower training and has trained more than adequate medical, dental and paramedical workers. Almost all the states have medical/dental colleges and Schools of Health Technology. The health system is relatively rich in human resources compared to many other African countries with 2 health care professionals/1000 populations (WHO benchmark is 2.5/1000). Many are unemployed yet the PHC system suffers from inadequate staffing of health facilities. Of the 277 PHC facilities in Lagos State, less than 20 have full complement of staff for 24 hours service.

One major evolving challenge is unionism. Instead of the PHC team spirit and intersectoral collaboration, some professional unions are at logger-heads with one another.

Also, there still exist controversies over the relevance of Traditional Birth Attendants' functions. Even in urban Lagos State where there are more than enough health facilities, TBAs still take more than $50 \%$ of deliveries. The state's Traditional Medicine Board has registered and trained more than 4000 of them. Evidence of their usefulness is described in the report on the Bill and Melinda Gates Maternal and Neonatal Project in Gombe, northern Nigeria where TBAs over a period of 6 months visited 54946 women, conducted 7150 deliveries, transported 985 women in labour and referred to health facilities 41775 maternal and neonatal patients [12].

\section{Funding of PHC}

The sources of funds are still the Federal Government through the NPHCDA, State Governments, LGs/LCDAs and Development Partners. Even though some states like Lagos have started experimenting with community-based insurance scheme, payment for service is still mostly through Fee for Services and Drug Revolving Funds. Even though the National Health Insurance Scheme is still in a rudimentary stage it has potentials to improve coverage if the National Health Bill becomes operational. The bottlenecks with LG administrative staff will be drastically reduced.

For sustainability, WHCs must not rely solely on funds from government or partners. They must generate funds as counterpart to any from other sources. Commitment, rather than pumping of money into programmes may be more relevant in ensuring impact and sustainability.

\section{Challenges of community governing bodies for health}

The initial challenges of lack of take-off grant, office accommodation, conflicting roles will be minimized when the National Health Bill becomes operational. Reluctance of LGs/LCDAs to fund their LGHAs and WHCs may be because they are seen as rivals competing for allocations with existing staff and uncertainty about the time the Bill will become operational [13-22].

\section{Conclusion}

There are positive outcomes from commencement of the implementation of the country's Health Reform Laws and Strategic Development Plans. States (Lagos State as index) are taking positive steps towards community ownership by enabling community governing bodies to assume leadership roles and take active part in the planning, implementation, monitoring and evaluation of their communities' health interventions. The challenges are still basically inadequate financing of health, non-engagement of trained manpower, inadequate and poor distribution of available human resource, and inadequate community mobilization resulting in sustainability problems.

\section{Recommendations}

For a sustainable PHC system in Nigeria each ward needs to develop costed Annual Operational Plan of Action based on community diagnosis, prioritize the problems, assess available resources and utilise them optimally. Ward Action Plans from all the wards in an LG/LCDA approved by the LGHA should constitute the LG/LCDA PHC Operational Action Plan while Action Plans from all the LGHAs in a state approved by the State's PHC Board/Agency should constitute the State Operational Action Plan. Plans will be funded by all relevant stakeholders in addition to allocations from government.

\section{References}

1. WHO Alma Ata Declaration (1978)

2. FMOH (2009) National Strategic Health Development Plan 2009- 2015.

3. WHO (2008) Primary Health Care Now More Than Ever. The World Health Report, 2008.

4. FMOH (2012) Saving Newborn Lives In Nigeria: Newborn Health page 15 
Citation: Abosede and Sholeye (2014) Strengthening the Foundation for Sustainable Primary Health Care Services in Nigeria. Primary Health Care 4: 167. doi:10.4172/2167-1079.1000167

Page 9 of 9

5. Lagos State SMOH (2006) Lagos State Health Reform Law 2006

6. WHO (2012) World Health Report 2012, Health Systems: Improving Performance. Geneva

7. McPake B, Hanson K, Mills A (1993) Community financing of health care in Africa: an evaluation of the Bamako initiative. Soc Sci Med 36: 1383-1395.

8. Lagos State Ministry of Health and UNICEF. (2012) Reducing Health Disparities in Lagos State: An Investment Case Study: 4-7.

9. Abosede OA, Campbell PC, Olufunlayo T, Sholeye OO (2012) Establishing a Sustainable Ward Health System in Nigeria: Are Key Implementers Well informed. J. Community Med Health Education Vol 2: 7

10. Ghana Health Service. National Malaria Control Programme.

11. Groups.google.com/forum/

12. Marchant T (2013) Maternal and Newborn Health Care: Baseline Findings From Gombe State, Nigeria.
13. Darmstadt GL, Donnay F and Starrs A (2013) The Connection Between Healthy Mothers and Healthy Newborns.

14. Chuma J, Okungu V (2011) Viewing the Kenyan health system through an equity lens: implications for universal coverage. See comment in PubMed Commons below Int J Equity Health 10: 22.

15. Africa Public Health Alliance and 15 plus Campaign.

16. WHO Rio Declaration

17. Luis Gomes Sambo, Josses Muthuri Kirigia, Juliet Nabyonga Orem (2013) Health financing in the African Region: 2000-2009 data analysis.

18. World Health Organization (2012) Word Health Statistics.

19. World Bank. Health Expenditure per capita.

20. FMOH (2009)Nigeria National Demographic Health Survey, 2008

21. FMOH (2013) Nigeria National Demographic Health Survey, 2013

22. Global Forum (2004) The10/90 Report on Health Research 2003-2004 "Global Forum for Health Research. 